\title{
HIF-1 mediated activation of antimicrobial peptide LL-37 in type 2 diabetic patients
}

\author{
Soumitra Mohanty ${ }^{1}$ (D) Witchuda Kamolvit ${ }^{1,5}$. Silvia Zambrana ${ }^{2,3}$. Eduardo Gonzales ${ }^{3}$. Jonas Tovi ${ }^{4}$. \\ Kerstin Brismar ${ }^{2} \cdot$ Claes-Göran Östenson $^{2} \cdot$ Annelie Brauner ${ }^{1}$ (])
}

Received: 3 March 2021 / Revised: 20 August 2021 / Accepted: 24 August 2021 / Published online: 15 October 2021

(C) The Author(s) 2021, corrected publication 2022

\begin{abstract}
Infections are common in patients with diabetes, but increasing antibiotic resistance hampers successful bacterial clearance and calls for alternative treatment strategies. Hypoxiainducible factor 1 (HIF-1) is known to influence the innate immune defense and could therefore serve as a possible target. However, the impact of high glucose on HIF-1 has received little attention and merits closer investigation. Here, we show that higher levels of proinflammatory cytokines and $C A M P$, encoding for the antimicrobial peptide cathelicidin, LL-37, correlate with HIF-1 in type 2 diabetic patients. Chemical activation of HIF-1 further enhanced LL-37, IL-1 $\beta$, and IL-8 in human uroepithelial cells exposed to high glucose. Moreover, HIF-1 activation of transurethrally infected diabetic mice resulted in lower bacterial load. Drugs activating HIF-1 could therefore in the future potentially have a therapeutic role in clearing bacteria in diabetic patients with infections where antibiotic treatment failed.
\end{abstract}

\section{Key messages}

- Mohanty et al. "HIF-1 mediated activation of antimicrobial peptide LL-37 in type 2 diabetic patients."

Annelie Brauner

Annelie.Brauner@ki.se

1 Department of Microbiology, Tumor and Cell Biology, Division of Clinical Microbiology, Karolinska Institutet and Karolinska University Hospital, 17176 Stockholm, Sweden

2 Department of Molecular Medicine and Surgery, Karolinska Institutet, Stockholm, Sweden

3 Area de Farmacologia, Facultad de Ciencias Farmacéuticas Y Bioquimicas, Instituto de Investigaciones Farmaco Bioquimicas, Universidad Mayor de San Andres, La Paz, Bolivia

4 Capio Health Care Center, Solna, Sweden

5 Faculty of Medicine Siriraj Hospital, Mahidol University, Bangkok, Thailand
- Our study highlights induction of the antimicrobial peptide, LL-37, and strengthening of the innate immunity through hypoxia-inducible factor 1 (HIF-1) in diabetes.

- Our key observations are:

1. HIF-1 activation increased LL-37 expression in human urothelial cells treated with high glucose. In line with that, we demonstrated that patients with type 2 diabetes living at high altitude had increased levels of the LL-37.

2 . HIF- 1 activation increased IL- $1 \beta$ and IL-8 in human uroepithelial cells treated with high glucose concentration.

3. Pharmacological activation of HIF-1 decreased bacterial load in the urinary bladder of mice with hereditary diabetes.

- We conclude that enhancing HIF-1 may along with antibiotics in the future contribute to the treatment in selected patient groups where traditional therapy is not possible.

Keywords HIF-1 - LL-37 · Cytokines · Type 2 diabetes · Urinary tract infections

\section{Introduction}

Patients with diabetes mellitus have an increased risk of infections, especially urinary tract infections, often recurrent and with enhanced severity [1]. Moreover, the heightened antibiotic resistance is a global threat, and novel treatment strategies are therefore mandatory.

The innate immune response including antimicrobial peptides and cytokines produced by uroepithelial cells plays an important role in preventing infections. Hypoxiainducible factor 1 (HIF-1) is a major regulator of cellular adaptation to low oxygen conditions. Its activity is dependent on the degradation of the HIF- $1 \alpha$ subunit in normoxia regulated by $\mathrm{O}_{2}$ dependent hydroxylation of the proline residue by prolyl hydroxylase domain protein 2 (PHD2). This promotes binding of the von Hippel-Lindau protein (VHL), leading to ubiquitination and proteasomal degradation, 
whereas inactivation of PHD2 activates the HIF-1 signaling $[2,3]$. HIF-1 has been studied in normoglycemic conditions and is involved in regulating inflammation and production of antimicrobial peptides [4], in particular LL-37 [5, 6], an antibacterial peptide, inactivating drug-sensitive and resistant bacteria by forming discrete membrane lesions and inhibiting the cell wall, nucleic acid, and protein biosynthesis [7-9]. A major difference to conventional antibiotics is that resistance seldom develops, making antimicrobial peptides a possible novel complement to treat specific infections [10]. Interestingly, in acute pyelonephritis, metabolic acidosis stimulates HIF-1 which further induces LL-37 expression in the renal collecting ducts [11]. Mice lacking HIF- $1 \alpha$ in their myeloid lineage showed less bactericidal activity when infected with group A streptococci and had less ability to prevent systemic bacterial spread [12]. In addition, HIF-1 was shown to have effect on uropathogenic Escherichia coli infection [5]. Although hypoxia alone can induce HIF-1 activation, high glucose levels, as can be found in diabetes, is known to impair the stability and function of HIF-1 [3, 13], but the impact of glucose on the immune response and infections is less well studied, in spite of the increased risk of serious complications during hyperglycemia. It is worthy of note that urinary tract infections may even be life-threatening in patients with diabetes. Exploring the effect during hyperglycemia of HIF-1 on infections could therefore open new avenues of treatment. Pharmacological inducers activating HIF-1, like dimethyloxalylglycine (DMOG) or deferoxamine (DFO), have been shown to partly restore the HIF-1 function in diabetes [14] and increase the expression of phosphoglycerate kinase 1 (PGK1). This promotes glycolysis using the AKT signaling pathway [15] which also plays an important role in insulin signaling and expression of antimicrobial peptides [16] and may therefore possibly also indirectly affect bacterial clearance.

To fill the knowledge gap, we evaluate the possible impact of high altitude on innate immune response, and to assess the option to enhance the epithelial defense against invading uropathogenic $E$. coli in diabetes, we investigated the potential effect of activating HIF-1 under hypoxic and high glucose conditions in vitro as well as in diabetic mice and in patients with type 2 diabetes.

\section{Methods}

\section{Collection of urine and serum from patients with type 2 diabetes}

Urine and venous blood samples from patients with type 2 diabetes were collected separately at outpatient clinics and taken care of at Karolinska University Hospital Laboratory and Universidad Mayor de San Andres between 2019 and 2020 and stored at $-80{ }^{\circ} \mathrm{C}$ prior to analysis. Urinary cells were immediately harvested for total RNA extraction. Nine out of twenty-three patients in La Paz were male, median age 61 (44-74) years, BMI 30.5 (22.5-40.8) $\mathrm{kg} \mathrm{m}^{-2}$, and HbA1c 56 (36-116) mmol mol ${ }^{-1}$. Twenty-one out of twentyfive in Stockholm were male with median age 67 (44-80) years, BMI 30.3 (24-40.2) $\mathrm{kg} \mathrm{m}^{-2}$, HbA1c 50 (40-73) mmol $\mathrm{mol}^{-1}$. Patients with known co-morbidities, like recurrent urinary tract infections, or on estrogen therapy were excluded. A detailed description of clinical parameters is given in Table 1.

\section{Bacterial strain and cell culture conditions}

Uropathogenic E. coli strain CFT073 expressing type 1 and $\mathrm{P}$ and $\mathrm{S}$ fimbriae along with $\alpha$-hemolysin was used in all experiments. For in vitro experiments, human uroepithelial cell lines, TERT-NHUC (kindly provided by M. A. Knowles, Leeds, UK), and 5637 (HTB-9, American Type Culture Collection) were used. To mimic hyperglycemia and high altitude, cells were exposed to $30 \mathrm{mM}$ glucose and hypoxia $\left(1 \% \mathrm{O}_{2}\right)$ as compared to normal glucose levels of either 5.5 or $6 \mathrm{mM}$ and normoxia with $21 \% \mathrm{O}_{2}$. Mannitol (Sigma) was used to verify the osmotic effect of glucose. For HIF-1 activation, $400 \mu \mathrm{M}$ of HIF-hydroxylase inhibitor, 2-oxoglutarate analogue DMOG (Frontier Scientific) or $100 \mu \mathrm{M}$ of iron chelator, DFO (Sigma) was used. DMOG effectively inhibits multiple $20 \mathrm{OG}$ dioxygenase and activates HIF-1 and might influence nucleic acid repair and fatty acid metabolism where $20 \mathrm{OG}$ dioxygenase is greatly involved [17]. During infection, DMOG was used to avoid possible influence on bacterial growth by the iron chelator, DFO.

\section{Mouse model of urinary tract infection}

Mouse experiments were approved by the Northern Stockholm Animal Ethics Committee and experiments were carried out according to the guidelines of the Federation of Laboratory Animal Science Association and in compliance with the Committee's requirements (10,370-2018). Tenweek-old female mice with hereditary diabetes, $\mathrm{db} / \mathrm{db}$ (BKS (D)-Leprdb/JOrlRj) (Janvier Laboratories) with a median blood glucose of 24.9 (16.1-27.6) $\mathrm{mM}$ were used. The mice received DMOG $(320 \mathrm{mg} / \mathrm{kg})$ or DMSO intraperitoneally every second day for 7 days prior to infection. Mice were anaesthetized, transurethrally infected with $0.5 \times 10^{8}$ colonyforming units (CFU) of $E$. coli, sacrificed after $24 \mathrm{~h}$ and 7 days infection. Urinary bladders were cut open, washed with PBS to remove non-adherent bacteria, and lysed in PBS using Dounce's homogenizer. Total bacterial load was counted using CFU assay [18]. 


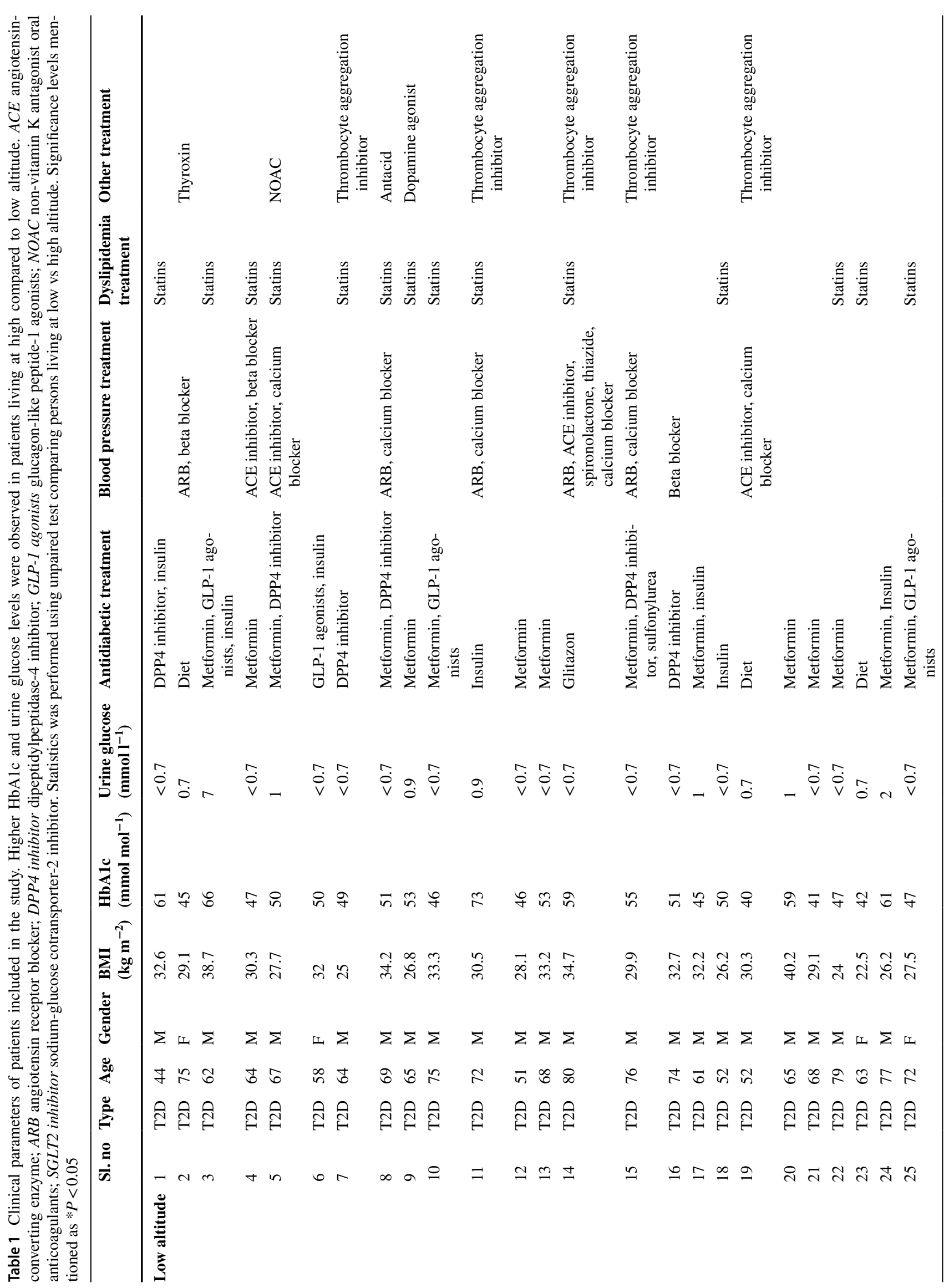




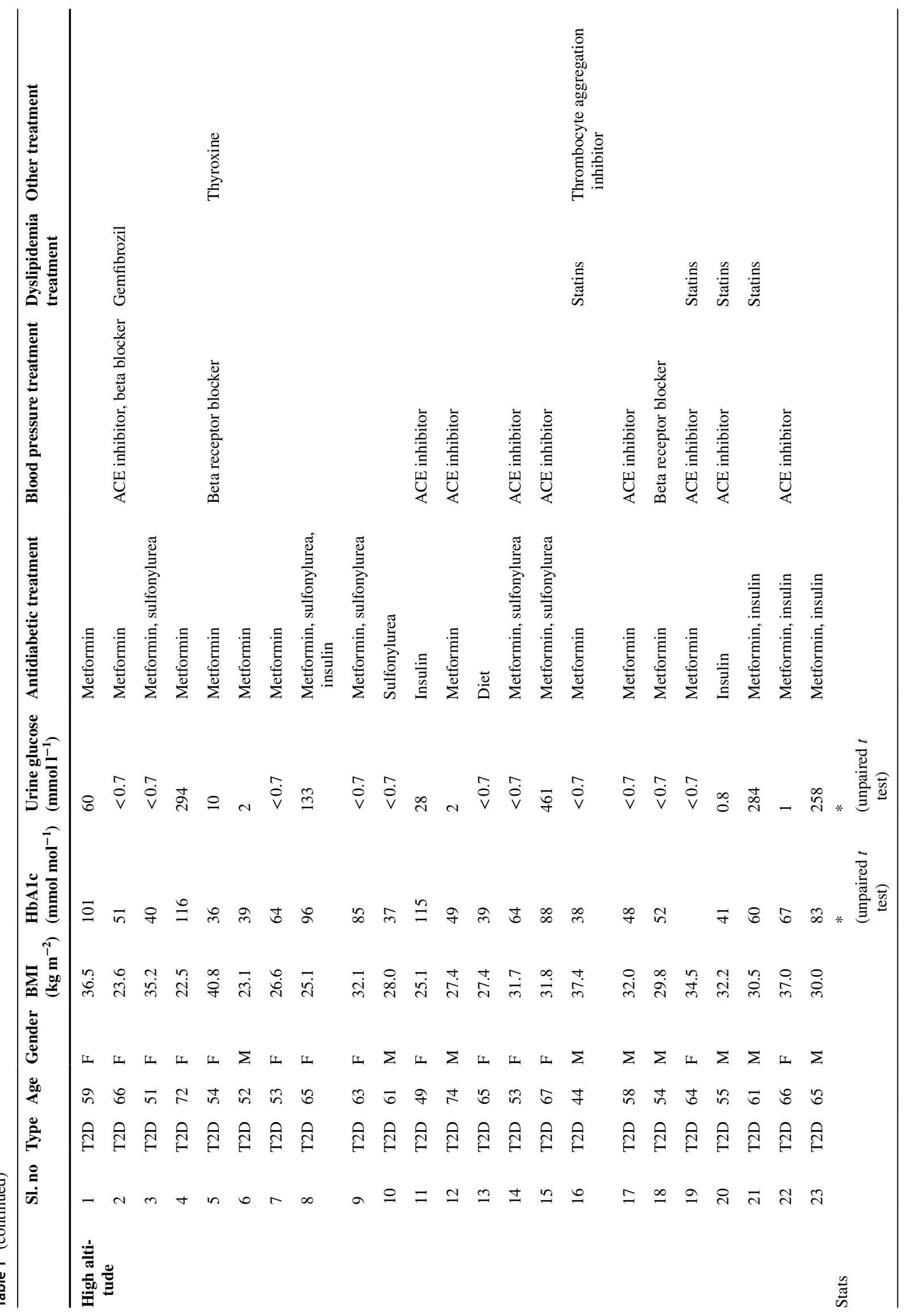




\section{Cell infection assay}

TERT-NHUC and 5637 cells were pretreated with glucose $(30 \mathrm{mM})$ with and without DMOG $(400 \mu \mathrm{M})$ and incubated in hypoxia $\left(1 \% \mathrm{O}_{2}\right)$ for at least $24 \mathrm{~h}$ followed by infection with $10^{6}$ E. coli. Cells were infected for $2 \mathrm{~h}$ with $E$. coli at MOI 10, washed with PBS to remove non-adherent bacteria, and supplemented with fresh medium for another $2 \mathrm{~h}$. To avoid possible interference of bacterial killing by the released antimicrobial peptides, no antibiotics were used. Furthermore, cells were washed with PBS, lysed with $200 \mu \mathrm{l}$ of $0.1 \%$ Triton X-100 in PBS (pH-7.4), and plated on blood agar plates. Bacterial load was calculated by a number of adhered and intracellular bacteria in relation to the total number of bacteria added from the same experiment.

\section{Reporter gene assay}

To assay the effect of glucose on the transcriptional activity of HIF-1, we used a plasmid (pT81/HRE-luc) that contains three tandem copies of the erythropoietin hypoxia response element (HRE) in front of the herpes simplex thymidine kinase promoter and the luciferase gene [19]. Human uroepithelial cells 5637 cultured in 24-well plates were transfected at $70-80 \%$ confluence with the reporter plasmid $(0.5 \mu \mathrm{g} /$ well), after changing the medium to Optimem (Life Science Technologies), using the FuGENE 6 transfection reagent (Roche Diagnostics) according to the manufacturer's instructions. After $6 \mathrm{~h}$, the medium was changed to RPMI containing either 5.5 or $30 \mathrm{mM}$ glucose. Cells were cultured in triplicate under hypoxic $\left(1 \% \mathrm{O}_{2}\right)$ or normoxic conditions $\left(21 \% \mathrm{O}_{2}\right)$. After $39 \mathrm{~h}$ of incubation, luciferase activity was determined as described by the manufacturer (Promega Biotec), and the reporter gene activity was standardized to protein content and expressed as fold induction relative to the activity under normoxic, normoglycemic conditions.

\section{qRT-PCR}

After the required incubation, TERT-NHUC cells were directly processed for RNA isolation, whereas bladder tissues were homogenized manually with Dounce's homogenizer. Total RNA was extracted using RNeasy mini kit (Qiagen) and transcribed to cDNA using a high-capacity cDNA synthesis kit (Applied Biosystems) according to the manufacturer's protocol. Up to $0.5 \mu \mathrm{g}$ of RNA was reverse transcribed using random primers for $10 \mathrm{~min}$ at $25^{\circ} \mathrm{C}, 120 \mathrm{~min}$ at $37^{\circ} \mathrm{C}$, and inactivation at $85^{\circ} \mathrm{C}$ for $5 \mathrm{~min}$. Real-time PCR was performed after initial denaturation at $95{ }^{\circ} \mathrm{C}$ for $10 \mathrm{~min}$, each cycle consisted of $15 \mathrm{~s}$ at $95^{\circ} \mathrm{C}, 60 \mathrm{~s}$ at $60^{\circ} \mathrm{C}$ (touchdown of $1{ }^{\circ} \mathrm{C}$ per cycle from $66^{\circ}$ to $60^{\circ} \mathrm{C}$ ), and $30 \mathrm{~s}$ at $72{ }^{\circ} \mathrm{C}$ using standard SYBR green and Taqman (Applied Biosystems) protocol in a Rotor-Gene PCR cycler (Corbett Life Science) [18]. Primer and probe details are mentioned in Table 2. Melting curves were produced at the end of the run with SYBR green to ensure the specificity of the amplification. Relative expressions of target genes were presented as $2^{-\Delta \mathrm{CT}}$ and fold change as $2^{-\Delta \Delta \mathrm{CT}}$ compared to respective control.

\section{Immunofluorescence staining}

Bladder sections were deparaffinized and rehydrated, pretreated with $0.3 \%$ Triton X-100 in PBS, or boiled in citrate buffer, $1 \mathrm{mM}$ EDTA, $10 \mathrm{mM}$ tris, $0.05 \%$ Tween 20 (pH 9). Cells were fixed in $4 \%$ PFA for either 5 or $30 \mathrm{~min}$ at room temperature and permeabilized with $0.1 \%$ Triton X-100 in PBS. Thereafter, cells were blocked with 5\% BSA in PBS for $30 \mathrm{~min}$; further sections were treated with FX Signal Enhancer (Invitrogen) at room temperature for $30 \mathrm{~min}$ to eliminate nonspecific fluorescence commonly seen with the application of fluorescent secondary antibody. To improve the specific fluorescence, sections were additionally blocked with the sera from the species in which the secondary antibodies were raised for $60 \mathrm{~min}$. Cells were
Table 2 Primers/probes used in the study

\begin{tabular}{llll}
\hline Primer & Forward $\left(\mathbf{5}^{\prime}-\mathbf{3}^{\prime}\right)$ & Reverse $\left(\mathbf{5}^{\prime} \mathbf{-} \mathbf{3}^{\prime}\right)$ & Reference \\
\hline Human $C A M P$ & ACCCAGCAGGGCAAATCT & GAAGGACGGGCTGGTGAA & {$[5]$} \\
Human HIFIA & GCTGGCCCCAGCCGCTGGAG & GAGTGCAGGGTCAGCACTAC & {$[45]$} \\
Human $P G K 1$ & AGTCCTTATGAGCCACCT & CAGAACATCCTTGCC CAG & {$[46]$} \\
Mouse & AGTCCGTTGTCCTTATGAG & CAGAACATCCTTGCCCAG & This study \\
Pgk1 & & & \\
Human $I L 1 B$ & CACGATGCACCTGTACGATCA & GTTGCTCCATATCCTGTCCCT & {$[47]$} \\
Human $C X C L 8$ & AAGAGAGCTCTGTCTGGACC & GATATTCTCTTGGCCCTTGG & {$[48]$} \\
Human $P B G D$ & AGGATGGGCAACTGTACC & GTTTTGGCTCCTTTGCTCAG & {$[49]$} \\
Mouse $P B G D$ & GTGTTGCACGATCCTGAAACT & GTTGCCCATCCTTTATCACTGTA & {$[49]$} \\
Probe & & & \\
Mouse & Mm00438285_m1 & & Invitrogen \\
Cramp & & & Invitrogen \\
Mouse $P B G D$ & Mm01143545_m1 & & \\
\hline
\end{tabular}




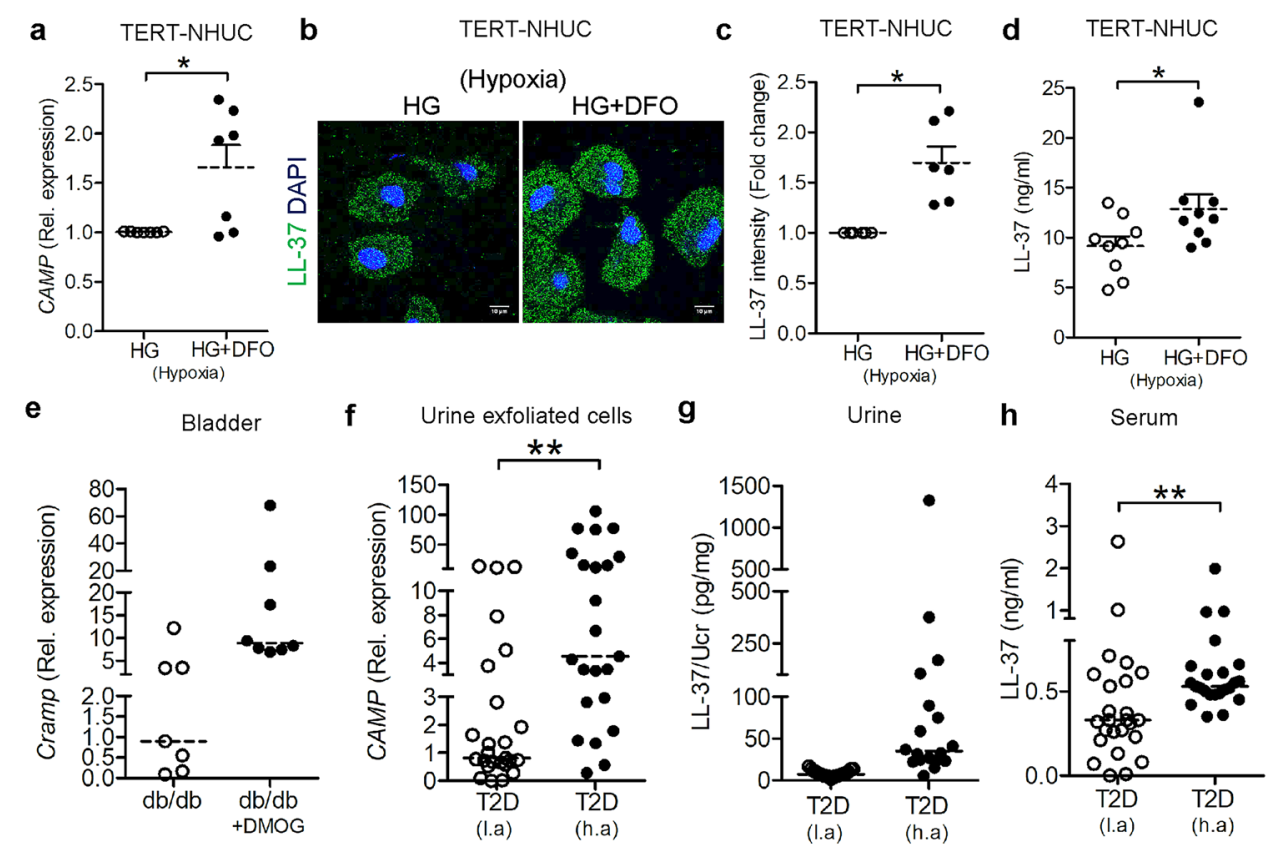

Fig. 1 HIF-1 activation increased expression of the antimicrobial peptide, LL-37, in diabetes. TERT-NHUC cells, demonstrating expression of a CAMP mRNA ( $n=7$, unpaired $t$ test) $24 \mathrm{~h}$ posttreatment. b Representative intracellular LL-37 stained $(n=6)$ with Alexa-488 (green) and DAPI (blue) for nucleus $36 \mathrm{~h}$ post-treatment. c Average fluorescence intensity LL-37 $(n=6$, Wilcoxon matchedpairs signed-rank test). d Secreted LL-37 levels $(n=3$, in triplicate, unpaired $t$ test) after $36 \mathrm{~h}$ treatment with DFO in hypoxia. e Cramp mRNA in DMOG $(n=8)$, DMSO treated $\mathrm{db} / \mathrm{db}$ mice $(n=7)$ urinary bladder 7 days post- $E$. coli infection (unpaired $t$ test). f Human urine exfoliated cells ( $n=25$ and 23, respectively, unpaired $t$ test) were ana-

stained with primary anti-LL-37 [20] (1:200, Santacruz) and anti-HIF-1 $\alpha$ [21] (1:100, BD) antibody in 1:1 ratio of $1 \times$ PBS with $0.1 \%$ Tween 20 (PBS-T) and 5\% BSA in PBS, sections with anti-E. coli (1:200; AbD Serotec), anti-UPIIIa (1:200; Santa Cruz) and incubated overnight at $4{ }^{\circ} \mathrm{C}$. Both sections and cells were washed with $1 \times \mathrm{PBS}-\mathrm{T}$ and further incubated with respective secondary Alexa Fluor-conjugated antibody (Invitrogen) in 1:600 (sections), 1:400, or 1:100 (cells) for $1 \mathrm{~h}$ at room temperature, followed by staining with DAPI for $15 \mathrm{~min}$, washed and mounted in Fluoromount G (Southern Biotech). Slides were analyzed with a Zeiss 700 confocal microscope using $63 \times$ oil immersion objective, from 3 to 5 random view fields per coverslip. Fluorescence intensity was quantified with the ImageJ software.

\section{ELISA}

Human serum and cell-free culture from in vitro experiments were collected using standard protocol [18]. LL-37 (Hycult Biotech), IL-1 $\beta$, and IL-8 (R\&D Biosystems) were analyzed according to the manufacturer's recommendations. lyzed for CAMP mRNA. g and human urine ( $n=19$ and 18 , respectively, unpaired $t$ test) for LL-37, normalized to urine creatinine (Ucr) and $\mathbf{h}$ serum ( $n=25$, unpaired $t$ test) from patients with type 2 diabetes (T2D) living at high altitude, La Paz, Bolivia, $3600 \mathrm{~m}$ above sea level, (h.a) and low altitude, Stockholm, Sweden, $28 \mathrm{~m}$ above sea level, (1.a) were analyzed for LL-37 protein. In vitro analysis was performed in either duplicate or triplicate. Average values are shown for each set. High glucose (HG). Data are shown as mean \pm SEM. Results from patients and mice are presented as median. Significance levels mentioned as $* P<0.05, * * P<0.01$, and $* * * * P<0.0001$

\section{Statistical analysis}

All statistical tests were performed in Graph pad Prism version 5. Data were obtained from Students' unpaired $t$-test, paired nonparametric two-tailed Wilcoxon matched-pairs, signed-rank test, and Pearson's correlation as appropriate. Differences with $p$ values below 0.05 were considered statistically significant.

\section{Results}

\section{Activation of HIF-1 increases LL-37 expression in diabetes}

Antimicrobial peptides are the first line to protect against invading microorganisms. We have previously demonstrated the importance of LL-37 in the human urinary tract [22]. However, the possible impact of HIF-1 on the antimicrobial peptide LL-37, encoded by CAMP in diabetes, is not fully understood and was therefore investigated. 


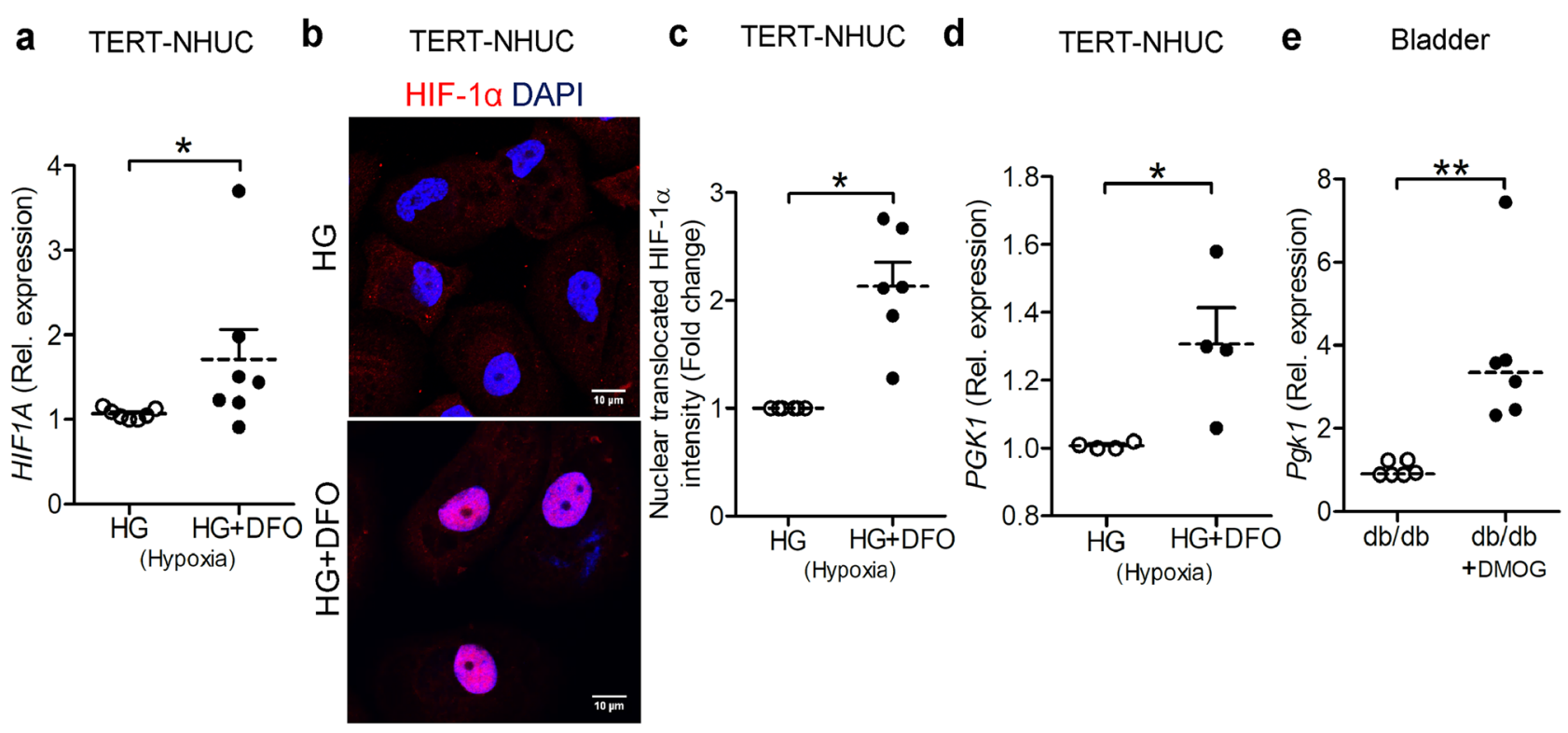

(Hypoxia)

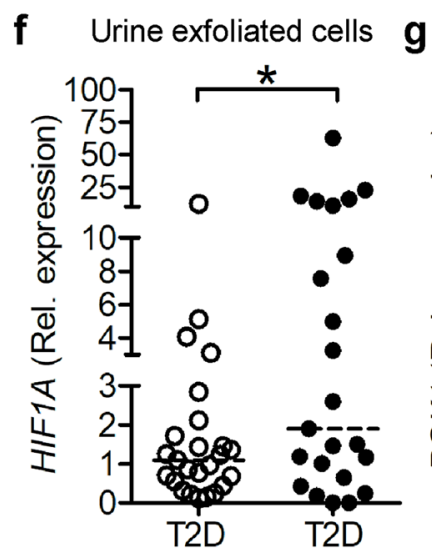

(l.a) g Urine exfoliated cells

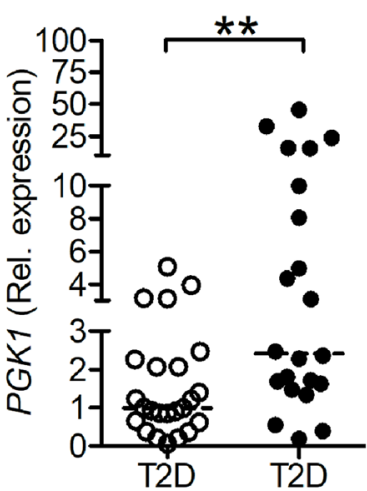

(I.a) h

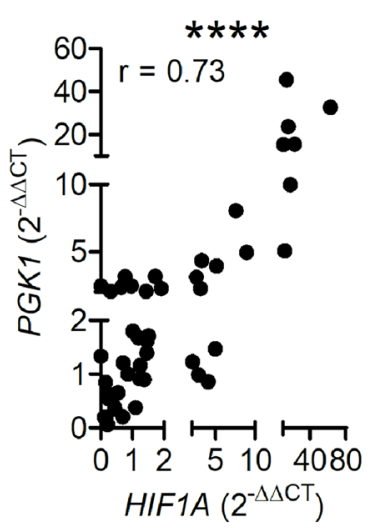

Urine exfoliated cells

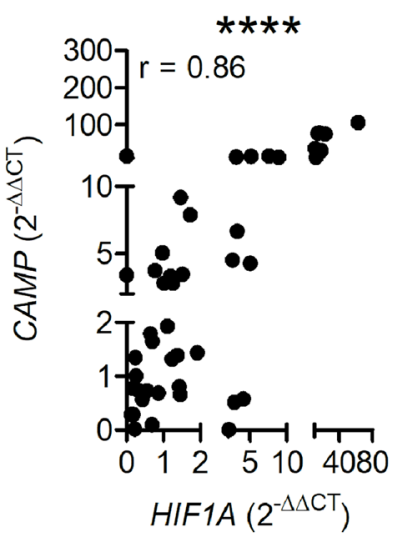

Fig. 2 Hypoxia and chemical activation of HIF-1 activates HIF target genes in diabetic urinary bladder. In TERT-NHUC cells, a expression of HIF1A mRNA ( $n=7$, unpaired $t$ test) $24 \mathrm{~h}$ post-treatment. b Nuclear translocation of HIF-1 $\alpha$ stained $(n=6)$ with Alexa-594 (red) and DAPI (blue) $36 \mathrm{~h}$ post-treatment, c nuclear HIF-1 $\alpha$ intensity ( $n=7$, Wilcoxon matched-pairs signed-rank test), and d PGK1 mRNA ( $n=4$, unpaired $t$ test) 24 h post-treatment. e Pgk1 expression in 7 days DMOG pretreated uninfected diabetes $\mathrm{db} / \mathrm{db}$ mice urinary bladder ( $n=6$, unpaired $t$ test). f HIF1A g PGK1 mRNA from urine exfoliated cells from patients with type 2 diabetes (T2D)

Cells cultured in hypoxia at a normal glucose concentration $(6 \mathrm{mM})$ showed increased expression of $C A M P$ while this was not observed at high glucose $(30 \mathrm{mM})$ or in normoxia (Fig. S1a). Furthermore, to investigate if high glucose levels affected the cells by its induced osmolarity, we exposed the cells to an identical high concentration of mannitol that is not metabolized by the exposed cells. We did not observe any difference with respect to $C A M P$ induction between high glucose and high mannitol stimulated cells, suggesting that the observed effect, at least partly, was mediated by

( $n=25$ and 23, respectively, unpaired $t$ test) living at high altitude, La Paz, Bolivia, $3600 \mathrm{~m}$ above sea level, (h.a) and low altitude, Stockholm, Sweden, $28 \mathrm{~m}$ above sea level, (l.a). Correlation graph showing expression of $\mathbf{h} P G K 1$ and $\mathbf{i} C A M P$ versus HIF1A ( $n=25$ and 23 , respectively, Pearson's correlation coefficient). In vitro experiments were performed in either duplicate or triplicate. Average values are shown for each set. High glucose (HG). Data are shown as mean \pm SEM. Results from patients and mice are presented as median. Significance levels mentioned as $* P<0.05$, $* * P<0.01$, and $* * * * P<0.0001$

hyperosmolarity (Fig. S1b). It cannot, however, be ruled out, that glucose as present in persons with diabetes can exert an additive and substrate-specific effect on LL-37 levels.

To activate the HIF-1, uroepithelial cells cultured in hypoxia and exposed to high glucose levels were treated with DFO. Indeed, treatment with DFO was followed by significantly increased CAMP mRNA (Fig. 1a), total intracellular LL-37 protein located in the cytoplasm, and within vesicles (Fig. 1b, c) as well as secreted LL-37 (Fig. 1d). To avoid the possible influence of DFO on E. coli, DMOG was used, 
which in addition has not been shown to affect blood glucose levels [23]. Likewise, diabetic, $\mathrm{db} / \mathrm{db}$ female mice infected with $E$. coli and pretreated with HIF-1 activator DMOG also showed a trend of increased expression of Cramp (Fig. 1e), while no difference was observed between uninfected mice with and without DMOG treatment (Fig. S1c, d). To mimic the activation of HIF-1, type 2 diabetic patients living at high altitude, La Paz, Bolivia (3600 m above sea level, masl), were included together with a corresponding patient group living at low altitude, Stockholm, Sweden (28 masl), serving as controls. Interestingly, in samples from patients living at high altitude, $C A M P$ expression was higher in urine exfoliated cells (Fig. 1f) After normalization to urine creatinine, LL-37 was detected in urine samples in seven out of 18 patients, but not from any of the patients living at low altitude (Fig. 1g). Moreover, higher serum LL-37 levels were detected in samples from patients living at high altitude (Fig. 1h) with no difference in the expression between male and female irrespective of altitude. To rule out a possible effect of different antidiabetic therapies on HIFl and $C A M P$, results were evaluated based on the treatment given, irrespective of altitude. No difference was observed between patients treated with insulin $(n=12)$ or drugs affecting the insulin signaling pathway, i. e., sulfonylurea and GLP-1 agonists $(n=8)$ or those treated with other oral antidiabetic drugs such as metformin, glitazon, DPP4, and SGLT2 inhibitors $(n=27)$ (Fig. S2a-b, Table 1).

\section{Chemical activation of HIF-1 and high altitude increases HIF-1 target genes in diabetes}

HIF-1 signaling triggers multiple genes, many of which are considered as HIF-1 target genes participating in the positive regulation of the HIF-1 function [24]. HIF-1also regulates the expression of several genes in diabetes [25]. To confirm the effect of high glucose on HIF-1, we transiently transfected uroepithelial cells 5637 with a HREdriven luciferase reporter gene, which generates a hypoxiadependent activation response [3]. Exposure of the cells to high glucose concentrations, under hypoxic conditions, produced slightly, although not significantly, lower activation (Fig. S3). To activate HIF1A, TERT-NHUC cells exposed to high glucose, hypoxia together with DFO, showed significantly increased HIF 1A mRNA (Fig. 2a). The stability of

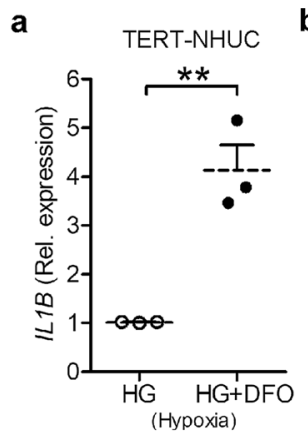

e Urine exfoliated cells $\mathbf{f}$

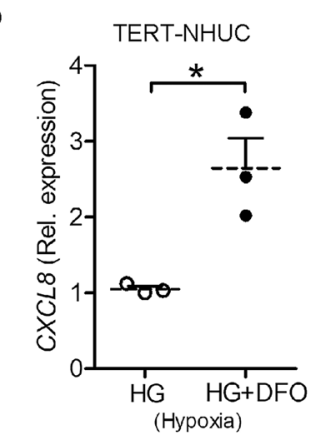

Urine exfoliated cells

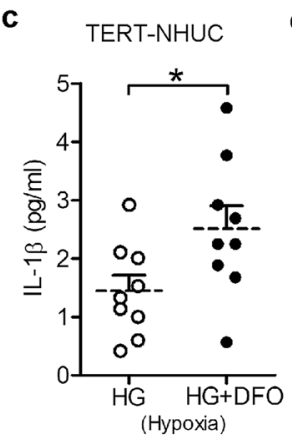

Urine exfoliated cells $\mathbf{h}$
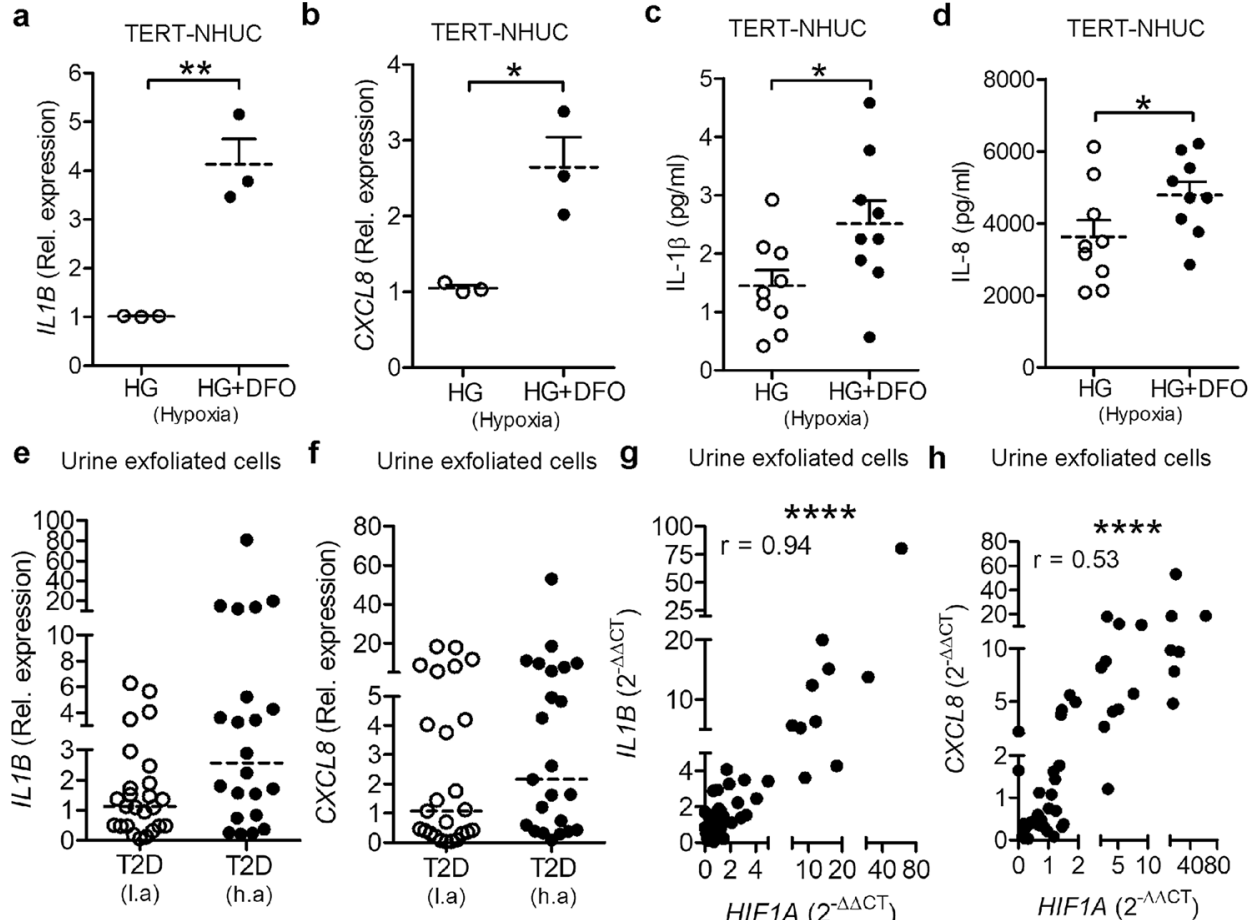

Urine exfoliated cells

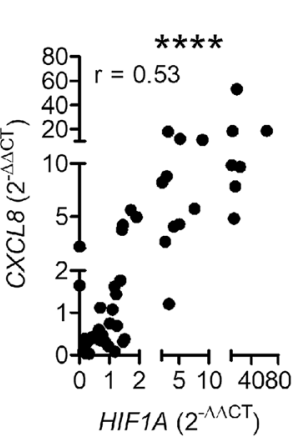

Fig. 3 HIF-1 activation increased proinflammatory cytokines. TERTNHUC cells expression of a ILIB b CXCL8 mRNA $(n=3$, unpaired $t$ test) $24 \mathrm{~h}$ post-treatment, $\mathbf{c}$ IL- $1 \beta$ and d IL- 8 protein $(n=3$, in triplicate, unpaired $t$ test) $36 \mathrm{~h}$ post-treatment with DFO in hypoxia. Urine exfoliated cells from patients with type 2 diabetes (T2D) patients living at high altitude in La Paz, Bolivia, $3600 \mathrm{~m}$ above sea level (h.a) and low altitude, Stockholm, Sweden, $28 \mathrm{~m}$ above sea level (1.a); ( $n=25$ and 23 , respectively, unpaired $t$ test), were analyzed for $\mathbf{e}$
$I L I B$ and $\mathbf{f} C X C L 8$. Correlation graph showing expression of $\mathbf{g} I L 1 B$ versus $H I F 1 A$ and $\mathbf{h} C X C L 8$ versus $H I F 1 A$ ( $n=25$ and 23, respectively, Pearson's correlation coefficient). In vitro experiments were performed in triplicate. Average values are shown for each set. High glucose $(\mathrm{HG})$. Data are shown as mean \pm SEM. Results from patients are presented as median. Significance levels mentioned as $* P<0.05$, $* * * P<0.001$, and $* * * * P<0.0001$ 
HIF-1 $\alpha$ was confirmed by its nuclear translocation (Fig. $2 b$, c) and increased expression of PGK1 (Fig. 2d). Similarly, DMOG-treated diabetic mice also showed increased $P g k 1$ mRNA in relation to non-treated mice (Fig. 2e). Interestingly, we observed significantly increased expression of HIFlA (Fig. 2f) and HIF-1 target gene PGKl (Fig. 2g) in exfoliated urine cells from type 2 diabetic patients living at high altitude. Moreover, we observed a direct correlation of PGKl (Fig. 2h) and CAMP (Fig. 2i) with HIFlA mRNA.

\section{HIF-1 activation increases proinflammatory cytokines in diabetes}

HIF-1 is known to be a positive regulator of cytokines namely IL-1A, IL-1B, and IL-6 in non-diabetic patients [26]. Cytokines are also involved in neutrophil infiltration, which helps in bacterial clearance [27]. Treatment with DFO of TERT-NHUC cells exposed to high glucose significantly upregulated $I L 1 B$ (Fig. 3a) and $C X C L 8$ (Fig. 3b) mRNA as well as secreted IL-1 $\beta$ (Fig. 3c) and IL-8 (Fig. 3d) protein levels. Similarly, the expression of the proinflammatory cytokine ILIB mRNA (Fig. 3e) and CXCL8 (Fig. 3f) showed a clear trend of increase with a high correlation to HIF IA mRNA levels in samples from type 2 diabetic patients living at high altitude (Fig. 3g, h).

\section{HIF-1 activation protects the host from E. coli infection in diabetes}

The uroepithelial, TERT-NHUC, and 5637 cells exposed to high glucose, hypoxia, and DMOG before E. coli infection had reduced bacterial load, compared to cells under the same conditions but without DMOG treatment (Fig. 4a, Fig. S4a). Similarly, diabetic mice, treated with DMOG before transurethral E. coli infection, showed lower bacterial load in the bladder compared with vehicle-treated mice at $24 \mathrm{~h}$ (Fig. 4b) with a minor but similar trend in the urine (Fig. S4b) and 7 days (Fig. 4c) post-infection. Interestingly, 7 days postinfection, the uroepithelium of all DMOG-treated mice was almost intact while in non-treated mice we observed disruption of the uroepithelial lining with pronounced $E$. coli load (Fig. 4d).

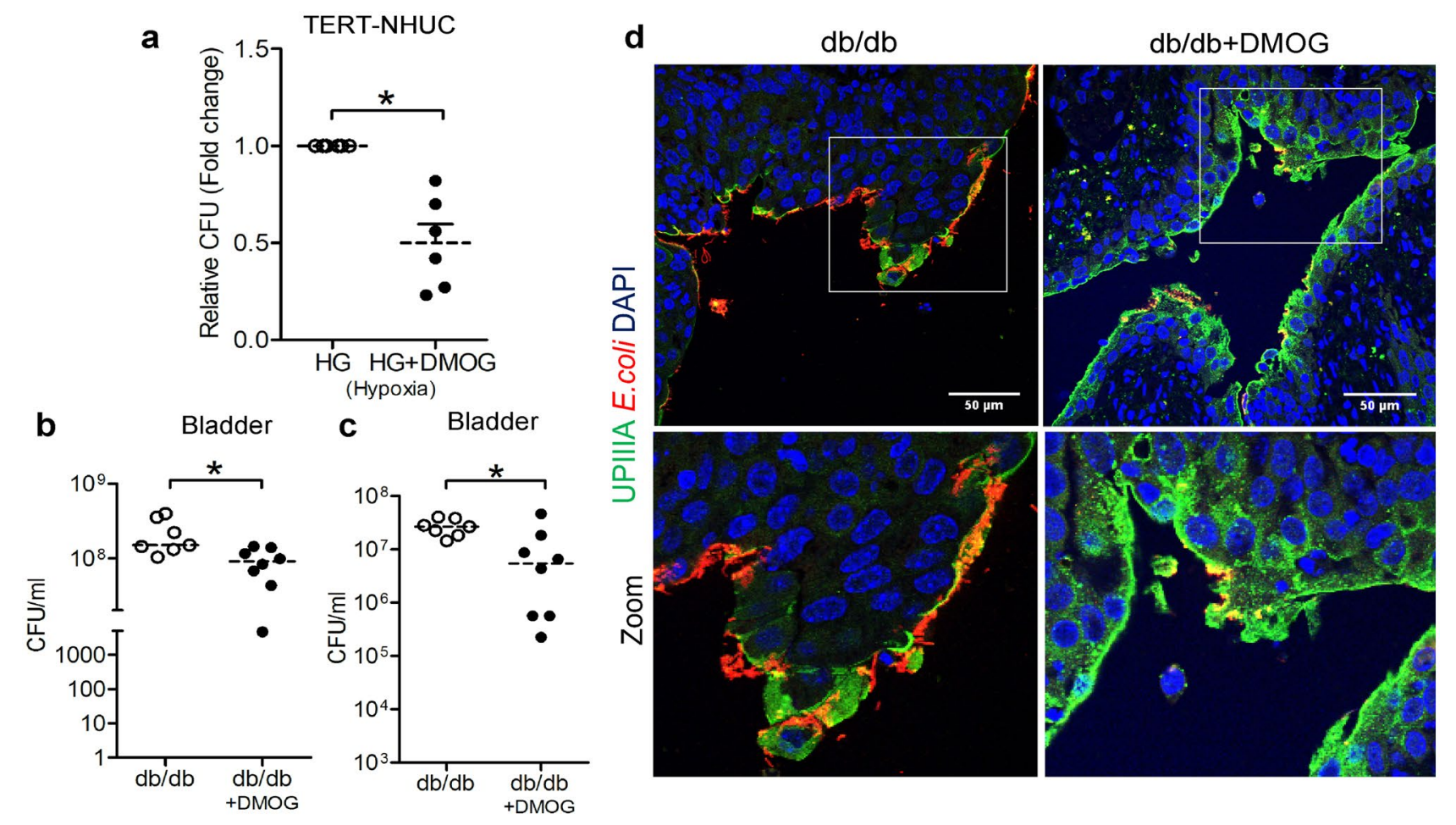

Fig. 4 HIF-1 activation decreased bacterial load in diabetic mice and uroepithelial cells. a Total number of bacteria in TERT-NHUC cells ( $n=6$, Wilcoxon matched-pairs signed-rank test) $24 \mathrm{~h}$ pretreated with vehicle or DMOG and urinary bladder from DMOG-treated diabetes, $\mathrm{db} / \mathrm{db}(n=8)$ and non-treated $(n=7)$ mice after b $24 \mathrm{~h}$ and $\mathbf{c} 7$ days using CFU, colony-forming unit assay (unpaired $t$ test). d Representative sections from mouse bladders from 7 days post-infection were stained for UPIIIa (marker of terminally differentiated umbrella cells, green) and E. coli (red), with DAPI to show nuclei (blue). L.p., lamina propria; $L u$., lumen; $E p$., epithelium. In vitro experiments were performed in either duplicate or triplicate. Data are shown as mean \pm SEM. Results from mice are presented as median. Significance levels mentioned as $* P<0.05$ and $* * * P<0.001$ 


\section{Discussion}

Preventing infections by strengthening the immune response is a tempting alternative to decrease antibiotic consumption. This is particularly important in patients with diabetes because of the frequent serious complications. Since diabetes is known to compromise several antimicrobial peptides like hBD-1, RNase4, RNase7, and LCN2 [16, 28, 29], our results are of special relevance and suggest a mode to reestablish the expression of antimicrobial peptides in type 2 diabetes patients. In normoxia and normal glucose conditions, HIF-1 regulates the expression of LL-37 [5] by binding to its promoter sequence [30]. As LL-37 in the urinary tract is vital to prevent urinary tract infections [31], it is important to secure high levels, especially in patients with diabetes. Moreover, apart from the antimicrobial activity, LL-37 may also regulate islet function and regeneration, thereby promoting glucose homeostasis [32] which may benefit the host during diabetes.

People living at high altitude are known to adapt to hypoxia, and modify the transcriptional response to the HIF pathway [26]. For the first time, we report the association of HIF-1 activation with the antimicrobial peptide LL-37 and HIF- 1 target genes $P G K I$ and $I L-I B$ in type 2 diabetic patients living at high altitude. Previously, a study including 25 non-diabetic individuals of Aymara ancestry from La Paz showed that the HIF pathway was mainly used to activate the genes including VEGFA and ILIB [33] along with several genes involved in oxygen homeostasis. In other tissues, like the adipose tissue, hypoxia has been shown to induce insulin resistance $[34,35]$. Since insulin resistance contributes to increased glucose levels, it cannot be ruled out that the increased $\mathrm{HbAlc}$ and urine glucose levels observed among patients from $\mathrm{La} \mathrm{Paz}$, in part, were a result of this. In patients with remaining endogenous insulin production, drugs acting on the insulin signaling pathway, like sulfonylurea and GLP-1 agonists, may have an impact on the results. This is particularly relevant since sulfonylurea may also act directly on this pathway by influencing the $\mathrm{K}_{\text {ATP }}$ channel. However, based on the antidiabetic treatment, we did not observe any difference with respect to HIFIA or CAMP.

It is well-known that diabetes is more common among men [36] whereas UTI is more frequent in women [37]. We have previously demonstrated the impact of estrogen on uroepithelial cells, showing increased LL-37 [18] and estrogen receptor $\alpha$, has been shown to directly regulate the HIF-1 pathway [38]. Moreover, studies using rats exposed to chronic hypoxia showed that males were more susceptible to hypoxic pulmonary hypertension and that estrogen was a key factor for protection in females [39].

In patients and mice with diabetes, bacterial clearance is compromised partly because of impaired cytokine expression [27, 40]. Improvement of cytokine expression in diabetes could therefore further enhance the immune response by promoting recruitment of immune cells which in turn could have a beneficial effect on infections. Our results highlighted HIF-1 mediated increased expression of IL- $1 \beta$ and IL- 8 even with cells exposed to high glucose. HIF-1 activation in diabetes and in high glucose-treated uroepithelial cells can efficiently restore the expression of proinflammatory cytokines which could benefit the host from invading pathogens. In normoxia, activation with DFO has not been consistent, and either up- or downregulation of IL- $1 \beta$ and IL- 8 has been demonstrated [5, 41]. However, since LL-37 is known to upregulate the expression of IL-1 $\beta$ [42], we cannot rule out a direct effect of LL-37 inducing IL-1 $\beta$ which in turn influences IL-8.

Furthermore, we highlight the importance of HIF-1 in reducing the bacterial load in high glucose-treated cells and in an in vivo infection UTI model. In concert with our results, non-diabetic people living at high altitude were shown to have decreased mycobacterial growth in whole blood compared to those from low altitude [43] suggesting the involvement of HIF-1 in the antibacterial activity. Our results also support previous findings of activated Hifl $\alpha$ upregulation of CRAMP [6] resulting in less C. albicans in the gastro-intestinal tract of normoglycemic mice. As CRAMP is highly antibacterial and mice lacking CRAMP are more susceptible to epithelial infections [12,44], this demonstrates an important role of cathelicidin in innate immunity.

In conclusion, we show an important role of HIF-1 activation in $E$. coli clearance in the presence of high glucose, pointing at a central role of HIF signaling in diabetic patients. We here also demonstrate the impact of high altitude on the immune response in type 2 diabetic patients. The increasing antibiotic resistance is globally a growing concern and fuels a need for alternative treatment strategies. Interest has therefore been focused on antimicrobial peptides. Although there are multiple hurdles, enhancing HIF-1 may, along with antibiotics, in the future complement and strengthen the immunity in selected patient groups where traditional treatment is not possible.

Supplementary Information The online version contains supplementary material available at https://doi.org/10.1007/s00109-021-02134-7.

Acknowledgements We thank Dr. Ujjwal Neogi for sharing the HIF-1 $\alpha$ antibody.

Author contribution S. M. and A. B. conceived and designed the experiments; S. M. and W. K. performed research; S. Z., E. G., J. T., and K. B., C-G. Ö. contributed human samples; C-G. Ö. and A. B. provided reagents/new analytic tools; S. M. and A. B. analyzed data; S. M. and A. B. wrote the paper; A. B. supervised the work. All authors read and approved the manuscript. 
Funding Open access funding providedby Karolinska Institute. This research was funded by the Stiftelsen Olle Engkvist Byggmästare, Region Stockholm (ALF project) and Swedish Neurological Association (AB). Swedish International Development Cooperation Agency (CGÖ, EG, SZ). Karolinska Institutet's Research Foundation (SM, WK, and $A B)$. WK was supported by grants from Siriraj Hospital Mahidol University, Thailand.

Data availability Data associated to this manuscript are saved in a data repository.

Code availability Not applicable.

\section{Declarations}

Ethics approval The human study was approved by the regional ethics review board in Stockholm (2010/723-31/2, 2018-03-26) and performed in accordance with the Helsinki Declaration.

Consent to participate Written and oral informed consent was obtained from all participants included in the study.

Consent for publication Not applicable.

Conflict of interest The authors declare no competing interests.

Open Access This article is licensed under a Creative Commons Attribution 4.0 International License, which permits use, sharing, adaptation, distribution and reproduction in any medium or format, as long as you give appropriate credit to the original author(s) and the source, provide a link to the Creative Commons licence, and indicate if changes were made. The images or other third party material in this article are included in the article's Creative Commons licence, unless indicated otherwise in a credit line to the material. If material is not included in the article's Creative Commons licence and your intended use is not permitted by statutory regulation or exceeds the permitted use, you will need to obtain permission directly from the copyright holder. To view a copy of this licence, visit http://creativecommons.org/licenses/by/4.0/.

\section{References}

1. Geerlings SE (2008) Urinary tract infections in patients with diabetes mellitus: epidemiology, pathogenesis and treatment. Int $\mathrm{J}$ Antimicrob Agents 31(Suppl 1):S54-57. https://doi.org/10.1016/j. ijantimicag.2007.07.042

2. Semenza GL (2007) Hypoxia-inducible factor 1 (HIF-1) pathway. Science's STKE: signal transduction knowledge environment 2007:cm8. https://doi.org/10.1126/stke.4072007cm8

3. Catrina SB, Okamoto K, Pereira T, Brismar K, Poellinger L (2004) Hyperglycemia regulates hypoxia-inducible factor-1alpha protein stability and function. Diabetes 53:3226-3232. https://doi. org/10.2337/diabetes.53.12.3226

4. Zinkernagel AS, Johnson RS, Nizet V (2007) Hypoxia inducible factor (HIF) function in innate immunity and infection. J Mol Med (Berl) 85:1339-1346. https://doi.org/10.1007/s00109-007-0282-2

5. Lin AE, Beasley FC, Olson J, Keller N, Shalwitz RA, Hannan TJ, Hultgren SJ, Nizet V (2015) Role of hypoxia inducible factor- $1 \alpha$ $(\mathrm{HIF}-1 \alpha)$ in innate defense against uropathogenic Escherichia coli infection. PLoS Pathog 11:e1004818. https://doi.org/10.1371/ journal.ppat.1004818
6. Fan D, Coughlin LA, Neubauer MM, Kim J, Kim MS, Zhan X, Simms-Waldrip TR, Xie Y, Hooper LV, Koh AY (2015) Activation of HIF- $1 \alpha$ and LL-37 by commensal bacteria inhibits Candida albicans colonization. Nat Med 21:808-814. https://doi.org/10. 1038/nm.3871

7. Xhindoli D, Pacor S, Benincasa M, Scocchi M, Gennaro R, Tossi A (2016) The human cathelicidin LL-37-a pore-forming antibacterial peptide and host-cell modulator. Biochem Biophys Acta 1858:546-566. https://doi.org/10.1016/j.bbamem.2015.11.003

8. Brogden KA (2005) Antimicrobial peptides: pore formers or metabolic inhibitors in bacteria? Nat Rev Microbiol 3:238-250. https://doi.org/10.1038/nrmicro1098

9. Haisma EM, de Breij A, Chan H, van Dissel JT, Drijfhout JW, Hiemstra PS, El Ghalbzouri A, Nibbering PH (2014) LL37-derived peptides eradicate multidrug-resistant Staphylococcus aureus from thermally wounded human skin equivalents. Antimicrob Agents Chemother 58:4411-4419. https://doi.org/ 10.1128/aac.02554-14

10. Lei J, Sun L, Huang S, Zhu C, Li P, He J, Mackey V, Coy DH, He Q (2019) The antimicrobial peptides and their potential clinical applications. Am J Transl Res 11:3919-3931

11. Peng H, Purkerson JM, Freeman RS, Schwaderer AL, Schwartz GJ (2020) Acidosis induces antimicrobial peptide expression and resistance to uropathogenic E. coli infection in kidney collecting duct cells via HIF-1 $\alpha$. Am J Physiol Renal Physiol 318:F468-f474. https://doi.org/10.1152/ajprenal.00228.2019

12. Peyssonnaux C, Datta V, Cramer T, Doedens A, Theodorakis EA, Gallo RL, Hurtado-Ziola N, Nizet V, Johnson RS (2005) HIF-1alpha expression regulates the bactericidal capacity of phagocytes. J Clin Investig 115:1806-1815. https://doi.org/10. $1172 /$ jci23865

13. Botusan IR, Sunkari VG, Savu O, Catrina AI, Grünler J, Lindberg S, Pereira T, Ylä-Herttuala S, Poellinger L, Brismar K et al (2008) Stabilization of HIF-1alpha is critical to improve wound healing in diabetic mice. Proc Natl Acad Sci USA 105:19426-19431. https:// doi.org/10.1073/pnas.0805230105

14. Catrina SB, Zheng X (2016) Disturbed hypoxic responses as a pathogenic mechanism of diabetic foot ulcers. Diabetes Metab Res Rev 32(Suppl 1):179-185. https://doi.org/10.1002/dmrr. 2742

15. Zhang Y, Cai H, Liao Y, Zhu Y, Wang F, Hou J (2020) Activation of PGK1 under hypoxic conditions promotes glycolysis and increases stem cell-like properties and the epithelial-mesenchymal transition in oral squamous cell carcinoma cells via the AKT signalling pathway. Int J Oncol 57:743-755. https://doi.org/10.3892/ ijo. 2020.5083

16. Eichler TE, Becknell B, Easterling RS, Ingraham SE, Cohen DM, Schwaderer AL, Hains DS, Li B, Cohen A, Metheny J et al (2016) Insulin and the phosphatidylinositol 3-kinase signaling pathway regulate Ribonuclease 7 expression in the human urinary tract. Kidney Int 90:568-579. https://doi.org/10.1016/j.kint.2016.04. 025

17. Rose NR, McDonough MA, King ON, Kawamura A, Schofield CJ (2011) Inhibition of 2-oxoglutarate dependent oxygenases. Chem Soc Rev 40:4364-4397. https://doi.org/10.1039/c0cs00203h

18. Luthje P, Brauner H, Ramos NL, Ovregaard A, Glaser R, Hirschberg AL, Aspenstrom P, Brauner A (2013) Estrogen supports urothelial defense mechanisms. Sci Transl Med 5:190ra180. https://doi.org/10. 1126/scitranslmed.3005574

19. Kallio PJ, Okamoto K, O’Brien S, Carrero P, Makino Y, Tanaka H, Poellinger L (1998) Signal transduction in hypoxic cells: inducible nuclear translocation and recruitment of the $\mathrm{CBP} / \mathrm{p} 300$ coactivator by the hypoxia-inducible factor-1alpha. EMBO J 17:6573-6586. https://doi.org/10.1093/emboj/17.22.6573 
20. Jatana S, Homer CR, Madajka M, Ponti AK, Kabi A, Papay F, McDonald C (2018) Pyrimidine synthesis inhibition enhances cutaneous defenses against antibiotic resistant bacteria through activation of NOD2 signaling. Sci Rep 8:8708. https://doi.org/10. 1038/s41598-018-27012-0

21. Appelberg S, Gupta S, Svensson Akusjärvi S, Ambikan AT, Mikaeloff F, Saccon E, Végvári Á, Benfeitas R, Sperk M, Ståhlberg M et al (2020) Dysregulation in Akt/mTOR/HIF-1 signaling identified by proteo-transcriptomics of SARS-CoV-2 infected cells. Emerg Microbes Infect 9:1748-1760. https://doi. org/10.1080/22221751.2020.1799723

22. Chromek M, Slamova Z, Bergman P, Kovacs L, Podracka L, Ehren I, Hokfelt T, Gudmundsson GH, Gallo RL, Agerberth B et al (2006) The antimicrobial peptide cathelicidin protects the urinary tract against invasive bacterial infection. Nat Med 12:636-641. https://doi.org/10.1038/nm1407

23. Zheng X, Narayanan S, Xu C, Angelstig SE, Grünler J, Zhao A, Toro AD, Bernardi L, Mazzone M, Carmeliet P et al (2021) Repression of hypoxia-inducible factor-1 contributes to increased mitochondrial reactive oxygen species production in diabetes. 2021.2006.2015.448500. https://doi.org/10.1101/2021.06.15. $448500 \%$ JbioRxiy

24. Semenza GL (2017) A compendium of proteins that interact with HIF-1 $\alpha$. Exp Cell Res 356:128-135. https://doi.org/10.1016/j. yexcr.2017.03.041

25. Catrina SB (2014) Impaired hypoxia-inducible factor (HIF) regulation by hyperglycemia. J Mol Med (Berl) 92:1025-1034. https:// doi.org/10.1007/s00109-014-1166-x

26. Bigham AW, Lee FS (2014) Human high-altitude adaptation: forward genetics meets the HIF pathway. Genes Dev 28:2189-2204. https://doi.org/10.1101/gad.250167.114

27. Ozer A, Altuntas CZ, Bicer F, Izgi K, Hultgren SJ, Liu G, Daneshgari F (2015) Impaired cytokine expression, neutrophil infiltration and bacterial clearance in response to urinary tract infection in diabetic mice. Pathog Dis 73. https://doi.org/10.1093/femspd/ftv002

28. Murtha MJ, Eichler T, Bender K, Metheny J, Li B, Schwaderer AL, Mosquera C, James C, Schwartz L, Becknell B et al (2018) Insulin receptor signaling regulates renal collecting duct and intercalated cell antibacterial defenses. J Clin Investig 128:5634-5646. https://doi.org/10.1172/jci98595

29. Brauner H, Luthje P, Grunler J, Ekberg NR, Dallner G, Brismar K, Brauner A (2014) type 2 diabetes mellitus and the effect of the anti-oxidant coenzyme Q10 on inflamMarkers of innate immune activity in patients with type 1 and matory activity. Clin Exp Immunol 177:478-482. https://doi.org/10.1111/cei.12316

30. Miraglia E, Nylén F, Johansson K, Arnér E, Cebula M, Farmand S, Ottosson H, Strömberg R, Gudmundsson GH, Agerberth B et al (2016) Entinostat up-regulates the CAMP gene encoding LL-37 via activation of STAT3 and HIF- $1 \alpha$ transcription factors. Sci Rep 6:33274. https://doi.org/10.1038/srep33274

31. Nielsen KL, Dynesen P, Larsen P, Jakobsen L, Andersen PS, Frimodt-Møller N (2014) Role of urinary cathelicidin LL-37 and human $\beta$-defensin 1 in uncomplicated Escherichia coli urinary tract infections. Infect Immun 82:1572-1578. https://doi.org/10. 1128/iai.01393-13

32. Pound LD, Patrick C, Eberhard CE, Mottawea W, Wang GS, Abujamel T, Vandenbeek R, Stintzi A, Scott FW (2015) Cathelicidin antimicrobial peptide: a novel regulator of islet function, islet regeneration, and selected gut bacteria. Diabetes 64:4135-4147. https://doi.org/10.2337/ db15-0788

33. Bigham AW, Mao X, Mei R, Brutsaert T, Wilson MJ, Julian CG, Parra EJ, Akey JM, Moore LG, Shriver MD (2009) Identifying positive selection candidate loci for high-altitude adaptation in Andean populations. Hum Genomics 4:79-90. https://doi.org/10. 1186/1479-7364-4-2-79
34. Rasouli N (2016) Adipose tissue hypoxia and insulin resistance. J Investig Med: The Official Publication of the American Federation for Clinical Research 64:830-832. https://doi.org/10.1136/ jim-2016-000106

35. Seo JB, Riopel M, Cabrales P, Huh JY, Bandyopadhyay GK, Andreyev AY, Murphy AN, Beeman SC, Smith GI, Klein S et al (2019) Knockdown of Ant2 reduces adipocyte hypoxia and improves insulin resistance in obesity. Nat Metab 1:86-97. https:// doi.org/10.1038/s42255-018-0003-X

36. Zimmet P, Alberti KG, Magliano DJ, Bennett PH (2016) Diabetes mellitus statistics on prevalence and mortality: facts and fallacies. Nat Rev Endocrinol 12:616-622. https://doi.org/10.1038/nrendo.2016.105

37. Shah BR, Hux JE (2003) Quantifying the risk of infectious diseases for people with diabetes. Diabetes Care 26:510-513. https:// doi.org/10.2337/diacare.26.2.510

38. Yang J, AlTahan A, Jones DT, Buffa FM, Bridges E, Interiano RB, Qu C, Vogt N, Li JL, Baban D et al (2015) Estrogen receptor- $\alpha$ directly regulates the hypoxia-inducible factor 1 pathway associated with antiestrogen response in breast cancer. Proc Natl Acad Sci USA 112:15172-15177. https://doi.org/10.1073/pnas.1422015112

39. Lahm T, Albrecht M, Fisher AJ, Selej M, Patel NG, Brown JA, Justice MJ, Brown MB, Van Demark M, Trulock KM et al (2012) $17 \beta$-Estradiol attenuates hypoxic pulmonary hypertension via estrogen receptor-mediated effects. Am J Respir Crit Care Med 185:965-980. https://doi.org/10.1164/rccm.201107-1293OC

40. Chanchamroen S, Kewcharoenwong C, Susaengrat W, Ato M, Lertmemongkolchai G (2009) Human polymorphonuclear neutrophil responses to Burkholderia pseudomallei in healthy and diabetic subjects. Infect Immun 77:456-463. https://doi.org/10. 1128/iai.00503-08

41. Simmen S, Cosin-Roger J, Melhem H, Maliachovas N, Maane M, Baebler K, Weder B, Maeyashiki C, Spanaus K, Scharl M et al (2019) Iron prevents hypoxia-associated inflammation through the regulation of nuclear factor- $\mathrm{\kappa B}$ in the intestinal epithelium. Cell Mol Gastroenterol Hepatol 7:339-355. https://doi.org/10.1016/j. jcmgh.2018.10.006

42. Kahlenberg JM, Kaplan MJ (2013) Little peptide, big effects: the role of LL-37 in inflammation and autoimmune disease. Journal of Immunology 191:4895-4901. https://doi.org/10.4049/jimmunol.1302005

43. Eisen S, Pealing L, Aldridge RW, Siedner MJ, Necochea A, Leybell I, Valencia T, Herrera B, Wiles S, Friedland JS et al (2013) Effects of ascent to high altitude on human antimycobacterial immunity. PLoS One 8:e74220. https://doi.org/10.1371/journal.pone.0074220

44. Peyssonnaux C, Boutin AT, Zinkernagel AS, Datta V, Nizet V, Johnson RS (2008) Critical role of HIF-1alpha in keratinocyte defense against bacterial infection. J Invest Dermatol 128:19641968. https://doi.org/10.1038/jid.2008.27

45. Choi HJ, Song BJ, Gong YD, Gwak WJ, Soh Y (2008) Rapid degradation of hypoxia-inducible factor-1alpha by KRH102053, a new activator of prolyl hydroxylase 2. Br J Pharmacol 154:114125. https://doi.org/10.1038/bjp.2008.70

46. Zheng X, Zhou AX, Rouhi P, Uramoto H, Borén J, Cao Y, Pereira T, Akyürek LM, Poellinger L (2014) Hypoxia-induced and calpain-dependent cleavage of filamin A regulates the hypoxic response. Proc Natl Acad Sci USA 111:2560-2565. https://doi. org/10.1073/pnas.1320815111

47. Sand J, Haertel E, Biedermann T, Contassot E, Reichmann E, French LE, Werner S, Beer HD (2018) Expression of inflammasome proteins and inflammasome activation occurs in human, but not in murine keratinocytes. Cell Death Dis 9:24. https://doi.org/ 10.1038/s41419-017-0009-4

48. Da Pozzo E, Giacomelli C, Cavallini C, Martini C (2018) Cytokine secretion responsiveness of lymphomonocytes following cortisol cell exposure: sex differences. PLoS One 13:e0200924. https://doi.org/10.1371/journal.pone.0200924 
49. Zheng X, Narayanan S, Sunkari VG, Eliasson S, Botusan IR, Grünler J, Catrina AI, Radtke F, Xu C, Zhao A et al (2019) Triggering of a Dll4-Notch1 loop impairs wound healing in diabetes. Proc Natl Acad Sci USA 116:6985-6994. https://doi.org/10.1073/ pnas. 1900351116
Publisher's Note Springer Nature remains neutral with regard to jurisdictional claims in published maps and institutional affiliations. 